\title{
V
}

\section{O ESTUDO SOCIAL NAS AÇÕES JUDICIAIS DE CURATELA À LUZ DO ESTATUTO DA PESSOA COM DEFICIÊNCIA / LEI BRASILEIRA DE INCLUSÃO*}

\section{Andreia Cristina Alves Pequeno ${ }^{1}$}

Este artigo tem como propósito abordar as alterações que a Lei Brasileira da Inclusão causou ao milenar instituto da interdição/curatela e problematizar a repercussão deste novo desenho legal na intervenção profissional do as sistente social no Judiciário. Ao buscar resguardar a autonomia e independência dos sujeitos com deficiência, a Lei Brasileira de Inclusão (LBI) ou Estatuto da Pessoa com Deficiência (EPD) redefine o papel do curador, construindo um novo parâmetro para a relação deste com o sujeito curatelado. Se num primeiro olhar esta mudança pode ser compreendida como positiva, em algumas situações pode resultar na fragilização do cuidado que deve se constituir como pilar da curatela. Este novo cenário impacta a construção dos estudos sociais e do parecer social ao convocar o assistente social a compor em sua avaliação o novo horizonte normativo com as situações factuais, e muitas vezes conflituosas, que lhe são apresentadas a partir das ações judiciais.

\section{O amparo jurídico do instituto da curatela}

Data do ano 450 a.c. uma norma na qual se encontra registro a respeito do instituto da curatela, nos seguintes termos: "Se alguém tornar-se louco ou pródigo e não tiver tutor, que a sua pessoa e seus bens sejam confiados à curatela dos $\operatorname{agnados}^{2}$ e, se não houver agnados, à dos gentis ${ }^{3}$." Trata-se de teor constante da Quinta Tábua, que tratava "Das heranças e tutelas" e que constituía a Lei das XII Tábuas, legislação vigente no período da República Romana e

*DOI - 10.29388/978-65-86678-28-4-0-f.113-128

${ }^{1}$ Assistente Social na Corregedoria Geral da Justiça/TJRJ; Mestrado em Serviço Social; Especialização em Geriatria e Gerontologia

2 Parente por agnação, ou seja, consanguinidade por linha masculina. Disponível em:< https://www.dicionarioinformal.com.br/agnado/>. Acesso em: 26 dez. 2019.

3 Gens são o tronco familiar muito antigo (ancestrais) e eram denominados gentilles. Disponível em: $<$ https://latim.paginas.ufsc.br/files/2012/06/A-Cidade-Antiga-Fustelde-Coulanges.pdf>. Acesso em: 26 dez. 2019. 
que pode ser considerada a primeira expressão do Direito Romano. (DHNET, LEI DAS XII TABUAS, 2019)

A curatela é, portanto, um instituto milenar que acompanha e se mantém na caminhada histórica dos homens, suportando as alterações estruturais e conjunturais edificadas ao longo de tantos séculos e atendendo aos interesses que se mostraram hegemônicos nesta trajetória.

Em que pese o registro de que a pessoa e seu patrimônio sejam submetidos à curatela, a bibliografia registra que por longo tempo o propósito do ins tituto guardava relação de fato com a proteção patrimonial e não com a proteção ao sujeito, conforme recupera Alves (2008, p. 676):

$[\ldots]$ no direito pré-classico, $[\ldots]$ tanto a tutela quanto a curatela eram institutos - segundo parece - de proteção, não ao incapaz, mas a seus futuros herdeiros, que, como tutores ou curadores, velavam pelo patrimônio que viria a ser deles, e exerciam, em vez de um dever, um verdadeiro poder ${ }^{4}$.

Em terras brasileiras, a curatela também contou com amparo jurídico. Inicialmente nas Ordenações Filipinas, normativa portuguesa promulgada pelo Rei Felipe I, em 1603, e que esteve em vigor por aqui até 1916, quando o Brasil República instituiu seu primeiro Código Civil, que seria substituído tão somente no século seguinte: 2002. Também os Códigos de Processo Civil abordam o tema.

Em 2015, sob influência da Convenção Internacional sobre os Direitos das Pessoas com Deficiência, aprovada em 2006 e ratificada pelo Brasil em 2008, foi aprovado o Estatuto da Pessoa com Deficiência, Lei 13.146, que explicitamente confere à curatela um novo formato por meio do qual se busca adensar a garantia dos direitos das pessoas com deficiência, afirmar sua autonomia e sua capacidade civil e coibir a banalização da curatela, bem como os abusos realizados por aqueles nomeados curadores.

\section{A construção histórico-legal de quem é o público absoluta- mente e relativamente incapaz}

As sociedades convencionaram adotar aparatos normativos como horizonte de regramento para as condutas e relações humanas, sob a premissa de

\footnotetext{
4 Além da obra de Alves, para uma visão mais aprofundada do tema é possível conferir Abreu, 2009 e Sá \& Moureira, 2011.
} 
que se cada um fizer como quiser, a sociedade resultaria numa desordem. Nesta perspectiva, leis são criadas para organizar o funcionamento da sociedade de modo a comandar seu modo de operar, definir parâmetros de conduta humana, determinar o certo e o errado, o crime e a pena, o que pode e o que não pode para uns e para outros.

É neste caldeirão de permanente ebulição, no qual distintos interesses, poderes, articulações e organizações disputam hegemonia, que se forjam as legislações e os diferentes contornos que a curatela adquiriu ao longo dos anos. $\mathrm{E}$ sempre em permanente interação com o tema da capacidade jurídica, já que se trata de instituto aplicado àqueles que são classificados como destituídos da capacidade civil que permite a cada um auto comandar todos os aspectos da própria vida. Não sendo detentor de capacidade civil, o sujeito tende a ser submetido à curatela, recebendo a nomeação de alguém para exercer a função de seu curador: aquele que irá cuidar do que o sujeito curatelado não tem capacidade para cuidar.

Segundo a legislação vigente no Brasil, aos 18 anos o indivíduo atinge a capacidade civil plena, podendo, então, exercer pessoalmente seus direitos e obrigações. Mas há situações em que, apesar de ter atingido a maioridade civil, o sujeito tem prejuízos em sua funcionalidade que impedem ou dificultam o exercício da capacidade civil, o que enseja a nomeação de um curador.

A avaliação da capacidade jurídica de alguém para fins de curatela é realizada por meio de uma ação judicial, que enseja um pronunciamento da autoridade judiciária que chancela se o sujeito necessita ou não da curatela, bem como define quem será o curador e cujos passos processuais estão regrados na legislação civil.

Em que pese a necessidade de avaliação individualizada para que se possa chegar a tais conclusões, a curatela até os dias atuais tem públicos destinatários previamente definidos na legislação. Definição edificada historicamente a partir de elementos balizados por perspectivas biológicas, acadêmicas, culturais e financeiras.

Um passeio pela legislação brasileira permite identificar que no que se refere à idade biológica, até o Código Civil de $2002^{5}$ pessoas menores de 21 anos eram consideradas absolutamente incapazes para os atos da vida civil. A

${ }^{5}$ O Código Civil de 2002 alterou para 18 anos a idade em que se atinge a maioridade civil, o que até então acontecia aos 21 anos. Entretanto, pelo Código Civil de 1916, as mulheres eram consideradas relativamente incapazes. Somente em 1962, com a Lei 4.121, as mulheres casadas passaram a ser consideradas pessoas civilmente plenamente capazes. 
partir de então, a maioridade civil passou a ser aos 18 anos e aqueles entre $16 \mathrm{e}$ 18 anos passam a ser considerados relativamente incapazes, resultando como plenamente incapazes tão somente os menores de 16 anos.

A concepção a respeito das deficiências e do adoecimento mental também recebe tratamento legislativo diferenciado ao longo do tempo, refletindo as mudanças socioculturais e ético-políticas e o conhecimento científico e acadêmico acumulado nas últimas décadas.

Às pessoas com deficiência e com transtorno mental por longo tempo foram ofertados: preconceito, pena, segregação, abandono, maus tratos, descrédito a suas potencialidades, negativa à possibilidade de convivência comunitária e até familiar. Trata-se de um modelo de tratamento legitimado, inclusive no plano legal, não somente por um padrão cultural de sustentação preconceituosa, mas também por posicionamentos de representantes da esfera acadêmico-cientifica e por políticas públicas.

Não é desconhecido que o Estado, seja na esfera federal, estadual ou municipal, financiou a segregação social da população atingida por deficiências e transtorno mental, mantendo este público - por décadas - em privação de liberdade e de convivência comunitária e familiar em diversas instituições públicas ou conveniadas que funcionaram em todos os cantos deste país. E muitas vezes, com funcionamento violador até mesmo de direitos básicos de sobrevivência, como alimentação, higiene, vestimenta e cuidados em saúde. Ocorrências como as do Hospital Colônia de Barbacena, em Minas Gerais, ${ }^{6}$ e da Clínica das Amendoeiras ${ }^{7}$, no Rio de Janeiro ilustram bem este cenário.

Entretanto, nas últimas décadas importantes movimentos de defesa dos interesses e dos direitos desta parcela populacional se fortaleceram no cenário nacional, conquistando significativas mudanças no plano legislativo e das políticas públicas para este contingente populacional. Embora o movimento de

${ }^{6}$ Hospital Colônia de Barbacena - é um dos sete hospitais psiquiátricos situados em Barbacena/MG. Inaugurado em 1903, chegou a acolher 5 mil pacientes em espaço projetado para 200 e foi alvo de denúncias de superlotação, de maus tratos e de venda de corpos para xxx. Foi comparado por Franco Basaglia a um campo de concentração. desumano. Em 1996, um de seus pavilhões foi transformado em museu. A história desta tragédia humana está retratada no livro "Holocausto Brasileiro, da jornalista Daniela Arbex (ARBEX, 2013).

${ }^{7}$ Clínica das Amendoeiras - foi instituição conveniada com o Sistema único de Saúde, situada no Rio de Janeiro/RJ recebia internação de pacientes com transtorno mental e com doenças neurológicas, teve seu funcionamento encerrado, em 2012, em decorrência de decisão judicial, em razão de haver sido constatado que os pacientes estavam submetidos a um ambiente degradante, com falta de higiene e inclusive, de alimentação adequada. 
pessoas com deficiência e o movimento da Reforma psiquiátrica tenham trilhado caminhos próprios e independentes, inclusive com amparos normativos específicos, tais como a Lei $7853 / 1989^{8}$ e a Lei $10.216 / 2001^{9}$, ambos defenderam a autonomia e a garantia de direitos deste público.

Em 2006, a Convenção sobre os Direitos da Pessoa com Deficiência/ONU incorporou a luta de ambos os movimentos e resguardou este contingente populacional sob o conceito de pessoa com deficiência, o que foi acompanhado pela Lei 13.146/2015. Assim, o conceito de pessoa com deficiência é alterado e ampliado, realocando o foco do sujeito para a sociedade e realçando a funcionalidade em detrimento da incapacidade:

Considera-se pessoa com deficiência aquela que tem impedimento de longo prazo de natureza física, mental, intelectual ou sensorial, o qual, em interação com uma ou mais barreiras, pode obstruir sua participação plena e efetiva na sociedade em igualdade de condições com as demais pessoas. (BRASIL, Lei 13.146/2015, art. 2 2019 )

O Estatuto da Pessoa com Deficiência (EPD) abarca ainda o tema da igualdade afiançando que "Toda pessoa com deficiência tem direito à igualdade de oportunidades com as demais pessoas e não sofrerá nenhuma espécie de discriminação" (BRASIL, Lei 13.146/2015, art. 42019). E atinge o debate da capacidade jurídica: "A pessoa com deficiência tem assegurado o direito ao exercício de sua capacidade legal em igualdade de condições com as demais pessoas" (BRASIL, Lei 13.146/2015, art. 84, 2019).

O EPD promove alterações no texto do Código Civil alterando os contornos do perfil populacional classificado como absoluta ou relativamente incapaz para os atos da vida civil, de modo a reduzir o escopo do grupo dos absolutamente incapazes, conforme apresentado no quadro a seguir:

8 Lei 7853/1989 - Dispõe sobre o apoio às pessoas portadoras de deficiência, sua integração social, sobre a Coordenadoria Nacional para Integração da Pessoa Portadora de Deficiência - Corde, institui a tutela jurisdicional de interesses coletivos ou difusos dessas pessoas, disciplina a atuação do Ministério Público, define crimes, e dá outras providências.

9 Lei 10216/2001 - Dispõe sobre a proteção e os direitos das pessoas portadoras de transtornos mentais e redireciona o modelo assistencial em saúde mental. 


\section{QUADRO 1. Definição de capacidades civil no Código Civil}

\begin{tabular}{|c|c|c|c|}
\hline & $\begin{array}{c}1916 \\
\text { CÓDIGO CIVIL }\end{array}$ & $\begin{array}{c}2002 \\
\text { CÓDIGO CIVIL }\end{array}$ & $\begin{array}{c}2015 \\
\text { LBI } \\
\text { CÓDIGO CIVIL }\end{array}$ \\
\hline $\begin{array}{l}\text { São absoluta- } \\
\text { mente incapazes } \\
\text { de exercer pes- } \\
\text { soalmente os } \\
\text { atos da vida ci- } \\
\text { vil: }\end{array}$ & $\begin{array}{l}\text { I - Os menores de } \\
\text { dezesseis anos. } \\
\text { II - Os loucos de } \\
\text { todo o gênero. } \\
\text { III - Os surdos- } \\
\text { mudos, que não } \\
\text { puderem exprimir } \\
\text { a sua vontade. } \\
\text { IV - Os ausentes, } \\
\text { declarados como } \\
\text { tais por ato do juiz. }\end{array}$ & $\begin{array}{l}\text { I - Os menores de } \\
\text { dezesseis anos; II - } \\
\text { os que, por enfer- } \\
\text { midade ou deficiên- } \\
\text { cia mental, não ti- } \\
\text { verem o necessário } \\
\text { discernimento para } \\
\text { a prática desses } \\
\text { atos; } \\
\text { III - Os que, mes- } \\
\text { mo por causa tran- } \\
\text { sitória, não pude- } \\
\text { rem exprimir sua } \\
\text { vontade }\end{array}$ & $\begin{array}{l}\text { Os menores de } 16 \\
\text { (dezesseis) anos. }\end{array}$ \\
\hline $\begin{array}{l}\text { São relativamen- } \\
\text { te incapazes, a } \\
\text { certos atos ou à } \\
\text { maneira de os } \\
\text { exercer: }\end{array}$ & $\begin{array}{l}\text { I - Os maiores de } \\
\text { dezesseis e os me- } \\
\text { nores de vinte e } \\
\text { um anos (arts. } 154 \\
\text { a } \\
\text { II - Os pródigos. }\end{array}$ & $\begin{array}{l}\text { a) Os menores entre } \\
16 \text { e } 18 \text { anos, cha- } \\
\text { mados menores pú- } \\
\text { beres; } \\
\text { b) Os ébrios, vicia- } \\
\text { dos em drogas e de- } \\
\text { ficientes mentais } \\
\text { com discernimento } \\
\text { reduzido; } \\
\text { c) Os excepcionais } \\
\text { sem desenvolvi- } \\
\text { mento mental com- } \\
\text { pleto; e d) os pródi- } \\
\text { gos. }\end{array}$ & $\begin{array}{l}\text { I - Os maiores de } \\
\text { dezesseis e menores } \\
\text { de dezoito anos; } \\
\text { II - Os ébrios habi- } \\
\text { tuais e os viciados } \\
\text { em tóxico; } \\
\text { III - aqueles que, } \\
\text { por causa transitó- } \\
\text { ria ou permanente, } \\
\text { não puderem expri- } \\
\text { mir sua vontade; } \\
\text { IV - Os pródigos. }\end{array}$ \\
\hline
\end{tabular}

Fonte: Quadro de elaboração própria.

Os pródigos, concebidos como aqueles que consomem em demasia suas finanças, permanecem como alvo da incapacidade relativa; enquanto ao indígena é apontado um tratamento a ser objeto de legislação específica. 
Em que pese a preciosa caminhada de alteração dos textos legais e o recente intento do parlamento em reconhecer a capacidade civil, ainda que relativa, de um público maior, faz-se necessário destacar dois aspectos.

O primeiro diz respeito ao aspecto contraditório que adquire a revisão dos contornos da capacidade civil, pois se por um lado confere a um público maior o reconhecimento de sua condição de sujeito capaz, por outro lado, nesta conjuntura de restrição de direitos, pode resultar na exclusão deste mesmo público da condição de dependente para acesso a determinados benefícios previdenciários. Já que para a atual legislação não existe mais pessoa maior de 18 anos que seja incapaz, mas tão somente relativamente incapaz, como ficará o acesso destes sujeitos a benefícios como pensão por morte? Farão faz jus a pensão decorrente da morte dos pais?

O segundo aspecto versa sobre o fato de que alguns conceitos ainda se mostram imprecisos; o que tem rebatimento nas avaliações técnicas a serem produzidas para iluminar a decisão judicial.

Afinal, que indicadores usar para definir quem é o ébrio habitual em um país onde o uso de bebida alcoólica faz parte da rotina do final de semana de tantos brasileiros? E os viciados em tóxicos, poderiam ser concebidos a partir do conceito de dependência química ou tão somente pelo uso recorrente? Como lidar com o conceito de "exprimir sua vontade", quando até crianças são capazes de exprimir vontades e quando adultos exprimem vontades de modo confuso e que em algumas situações lhes colocam em risco?

\section{O rito processual sob os novos paradigmas da LBI}

O EPD, edificado sob o paradigma da igualdade, da autonomia, da participação e da capacidade civil do sujeito com deficiência, traz inovações ao rito processual, superando a ideia de interdição, ampliando algumas possibilidades quanto à autoria da ação e do exercício da curatela. Mas, sobretudo, reforçando a ideia de que tendo a curatela natureza excepcional é fundamental que a avaliação de cada sujeito ocorra de modo individualizado, observando-se as particularidades de cada caso, de modo a aplicar o instituto tão somente quando de fato ele se mostra necessário e na medida exata da necessidade de proteção ao sujeito curatelado. 
Inclusive, o EPD ao incluir o artigo 110-A na Lei $\mathrm{n}^{\circ} 8.213 / 91^{10}$ assevera que o acesso a benefícios previdenciários e assistenciais não deve ser fundamento para a aplicação da curatela.

No ato de requerimento de benefícios operacionalizados pelo INSS, não será exigida apresentação de termo de curatela de titular ou de beneficiário com deficiência, observados os procedimentos a serem estabelecidos em regulamento. (BRASIL, Lei 13.146/2015, )

O EPD aboliu o uso da terminologia "interdição", embora ela esteja mantida no texto do Código de Processo Civil. Certamente, não sem motivo, este conceito está suprimido do texto legal, já que este busca ressaltar as potencialidades, as funcionalidades do sujeito.

Interdição é uma palavra tingida por um forte significado que favorece o imaginário de que ora interditado o sujeito nada mais pode, não tem vontade, está paralisado, impedido de tudo. E, provavelmente, foi assim que aconteceu para muitos que foram alvo de tais ações judiciais até então. Mas é exatamente este tipo de ocorrência que a legislação ora vigente busca extirpar. Ao focar no conceito de curatela, a proposta é ressaltar a perspectiva do cuidado, e cuidar adequadamente é respeitar e valorizar as potencialidades do sujeito, não o anular. Então:

A definição de curatela de pessoa com deficiência constitui medida protetiva extraordinária, proporcional às necessidades e às circunstâncias de cada caso, e durará o menor tempo possível. (BRASIL, Lei 13.146/2015)

Com o EPD torna-se possível que o curatelando seja autor da ação de nomeação de curador (art. 1768 / Código Civil).

O EPD inova quanto ao regramento dos poderes da curatela ao afirmar em seu art. 85 que "afetará tão somente os atos relacionados aos direitos de natureza patrimonial e negocial". E na sequência acrescenta que "não alcança o direito ao próprio corpo, à sexualidade, ao matrimônio, à privacidade, à educação, à saúde, ao trabalho e ao voto". Aqui novamente reforça o teor do art. 84: “A pessoa com deficiência tem assegurado o direito ao exercício de sua capacidade legal em igualdade de condições com as demais pessoas". (BRASIL, Lei 13.146/2015, art. 84))

${ }_{10}$ Lei no 8.213 , de 24 de julho de 1991. Dispõe sobre os Planos de Benefícios da Previdência Social e dá outras providências. 
A curatela deve ser aplicada não de forma banalizada, mas somente quando necessário (Brasil, Lei 10.406/2002, \ $1^{\circ}$, art. 84). E para uma adequada avaliação da necessidade de aplicação deste instituto, o juiz deve entrevistar pessoalmente o curatelando. Além disso, o juiz deve ser assistido por equipe multidisciplinar, ou seja, não basta mais apenas a avaliação do médico (Brasil, Lei 10.406/2002, art. 1771).

Para a escolha do curador, é preciso considerar a vontade do curatelado e "[...] dar preferência a pessoa que tenha vínculo de natureza familiar, afetiva ou comunitária com o curatelado", podendo o juiz aplicar a curatela compartilhada a mais de uma pessoa (BRASIL, Lei 10.406/2002, art.1.775-A). Ficou mantido o dever de prestação de contas pelo curador.

\section{O estudo social nas ações de curatela à luz do Estatuto da Pessoa com Deficiência}

Na realidade do Tribunal de Justiça do estado do Rio de Janeiro (TJRJ), há alguns anos o assistente social já tem sido demandado a elaborar estudo social em ações tipificadas como de interdição, nas quais se avaliam a capacidade dos sujeitos de comandarem a própria vida e a nomeação de curador.

Entretanto, não tem sido o assistente social convocado a atuar na totalidade de tais tipos de ações judiciais, embora não se tenha informações a respeito dos critérios adotados pelas autoridades judiciárias para selecionar em quais ações se requisita a atuação deste profissional.

Porém, ao longo dos anos parece ter se consolidado uma espécie de divisão no processo de avaliação técnica que ocorre em tais ações judiciais. Embora a legislação nunca tenha especificado qual especialidade profissional deve proceder tais avaliações, a medicina, em seu recorte psiquiátrico, tem liderado de modo preponderante as perícias no bojo de tais ações judiciais. Tal fato pode ser compreendido pela importância conferida ao diagnóstico médico, bem como pelo público alvo de tais ações judiciais que geralmente também é o público alvo dos atendimentos psiquiátricos.

Por sua vez, ao ingressar no cenário pericial de tais ações, o assistente social parece receber como demanda desvendar as relações sociofamiliares com $\mathrm{o}$ intuito de apontar quem deveria ser o curador.

Este arquétipo instituído até então parece sugerir que a definição da necessidade da curatela resultava meramente da definição do diagnóstico; quase tratando determinados diagnósticos como sinônimos de incapacidade civil. 
Trata-se de um modelo que caduca diante do avanço da luta por direitos que tem conquista expressa no atual ordenamento jurídico, o qual parte do princípio da igualdade e da capacidade civil das pessoas com deficiência e que requisita não mais um diagnóstico médico, mas uma avaliação com foco na autonomia e na funcionalidade do sujeito, visto que a curatela deve ser aplicada na estrita necessidade de cada caso.

Enquanto o diagnóstico é concebido como propriedade privada da medicina, a avaliação da autonomia e da funcionalidade convoca o pronunciamento de um amplo rol de profissões já que não se caracterizam como elementos que compõem a matéria privativa de uma determinada especialidade do saber. Entretanto, parece razoável compreender que não serão possíveis inúmeras avaliações por profissionais de diferentes especialidades em uma só ação judicial visto que isto implica em custo financeiro e em tempo de duração do processo, bem como na observação de que recursos humanos compõem o quadro de profissionais dos Tribunais, bem como seu rol de peritos externos. Assim, se não se tem dúvidas de que na vigência do EPD as avaliações técnicas são de natureza multidisciplinar, quais disciplinas atuarão neste contexto é uma questão que emerge na atualidade.

Fundamental também destacar que com o Estatuto da Pessoa com Deficiência o conceito de deficiência e de capacidade/incapacidade se aproximam, mas não podem ser tratados como sinônimos. À luz do EPD todas as pessoas com deficiência são pessoas plenamente capazes. A conclusão de que alguma destas tem relativizada sua capacidade decorre da avaliação de fatores que atingem sua autonomia, sua condição de manifestação de vontade e de discernimento, sua funcionalidade.

Esta ampla redefinição do escopo da perícia em ações de curatela alcança também ao assistente social, convocando-o a ampliar a abrangência de sua avaliação técnica para fortalecer a perspectiva expressa no EPD.

Há contribuição possível a ser ofertada pelo assistente social no debate sobre as funcionalidades do sujeito, que hoje parece ser o eixo central para uma decisão a respeito da curatela?

$\mathrm{O}$ assistente social, ao acumular expertise no conhecimento e análise das condições de vida e das relações sociais que constituem o aporte existencial do sujeito que é alvo da ação de curatela, acaba por colher informações também sobre como se materializa na vida cotidiana deste o exercício de sua autonomia e de sua funcionalidade para as diversas atividades que sustentam a existência humana. Assim, o profissional coleta uma diversidade de informações que versam sobre a condição existencial do sujeito que revelam sua atual capacidade de 
discernimento, mas que também podem apontar potencialidades, ou não, de ampliação de sua autonomia. E tudo isso dialoga com o conceito de capacidade civil.

Ao avaliar um sujeito com diagnóstico de Mal de Alzheimer, conhecendo que ainda não se tem tratamento que permita a cura da doença e conhecendo o prognóstico desta, infere-se com razoabilidade que não existem condições de significativa e duradoura melhora da autonomia e funcionalidade do sujeito. O uso da medicação especializada e o atendimento profissional multidisciplinar revelam o cuidado ofertado ao sujeito e poderá, no máximo, trazer qualidade de vida e postergar o avanço da doença. Entretanto, há diferença em efetivar uma avaliação técnica no momento de um quadro mais avançado da doença ou em seu estágio inicial, quando o sujeito ainda preserva funcionalidades e ainda tem condição de expressar suas vontades, desejos e opções.

Ao contrário de se avaliar um sujeito que há anos está privado de liberdade, contido por muros e rotinas institucionais psiquiatrizantes, diante do que não mais cabe concluir simplesmente que o mesmo está adaptado à instituição, pois esta não é lugar para que o mesmo seja mantido já que longas internações psiquiátricas estão coibidas pela Lei 10.216/2001. Neste caso, alçar o direito a viver em uma residência terapêutica, gozando do direto à vida, à liberdade e em convívio comunitário e com o suporte de acompanhantes terapêuticos anuncia perspectivas de potencialização da autonomia e da funcionalidade do sujeito.

Este novo modo de operar as avaliações nas ações de curatela permite ao assistente social se reposicionar adensando novos elementos à sua análise, ao seu estudo social e, consequentemente, ao desenho de seu Parecer Social. Superando, assim, mas não abandonando a questão do curador que ora alça absoluta relevância, já que precisa ser alguém que tenha sensibilidade para compreender e buscar implementar seu novo papel diante da resignificação do instituto da curatela. Assim, versar sobre aquele ou aqueles que podem ser o curador não é tarefa de menor valia e nem sem complexidade, sobretudo, sob a premissa de que a figura do curador deve estar atrelada à perspectiva do cuidado.

Neste momento histórico de fragilidade dos vínculos sociais e afetivos versar sobre o curador pode colocar o profissional diante de situações que parecem não apresentar nenhuma alternativa. Como versar sobre curador para pessoas que foram privadas da liberdade e dos vínculos familiares por sofrerem longos períodos de institucionalização? Como versar sobre curador para parcela da população que vive em situação de solidão, pois já enterrou todos os seus entes familiares? Como versar sobre curador para aqueles que vivem em solidão, pois seus vínculos afetivos e familiares se perderam na estrada da vida? 
Como versar sobre curador quando os entes familiares parecem preocupados tão somente com a herança que irão receber?

Reconhecendo que o assistente social não tem o poder de criar, de inventar um curador, tais desafios parecem inserir o debate sobre a curatela não só no novo desenho trazido pelo EPD, mas no bojo das políticas públicas ao se considerar que o cuidado é um direito humano, que curatelar tem como fundamento ser cuidado por alguém e de preferência por alguém com quem se tenha vínculo afetivo, que muitos brasileiros carecem de pessoas de referência que possam assumir sua possível curatela. Diante de tal cenário, não seria pertinente reposicionar a curatela, não somente como um encargo do indivíduo curador, mas também como um serviço a ser prestado pelo Estado?

Também a abrangência da atuação do curador é quesito primordial a ser abordado pelo assistente social. Embora o artigo 85 do EPD defina a atuação do curador no contexto financeiro, ele não deve ser compreendido de modo isolado, pois o propósito maior do Estatuto é a proteção do sujeito. Neste sentido, o artigo 84, afirma que "a definição de curatela de pessoa com deficiência constitui medida protetiva extraordinária, proporcional às necessidades e às circunstâncias de cada caso, e durará o menor tempo possível". (BRASIL. artigo 84 da Lei no 13.146/2015, acesso em 2019)

Ora, um artigo não tem mais poder que o outro e o propósito da Lei não deve ser minimizado diante de um de seus artigos. Se a curatela deve ser proporcional às necessidades de cada caso, é fundamental que a avaliação verifique se circundar a atuação do curador à dimensão financeira é adequado às necessidades do caso em apreço, de modo a se assegurar a efetiva proteção do sujeito e não somente de seu patrimônio; o que resultaria na proteção do interesse de futuros herdeiros e não do curatelado. A Lei é regra geral que abre possibilidades para que a curatela atenda seu efetivo propósito que é o cuidado ao sujeito curatelado, com base em seu propósito maior e em argumentos e fatos comprovados sobre a situação do sujeito. Certamente, o propósito do legislador ao limitar a atuação do curador à esfera monetária não foi permitir que o patrimônio do curatelado seja cuidado e investido em aplicações bancárias enquanto ele sofra necessidades materiais, pois o curador só tem que cuidar do dinheiro. Deste modo, o fundamento da gestão patrimonial é sua adequada administração para garantir o provimento das necessidades materiais do curatelado. Portanto, não se trata efetivamente de cuidar somente do dinheiro. Trata-se da boa administração patrimonial para cuidar do sujeito, que a depender de seu estado pode estar com sua condição de autonomia, de funcionalidade de expressão de vontade bastante reduzida, pode estar totalmente dependente até mesmo para as 
atividades mais básicas da vida diária, como é o caso, por exemplo, de um sujeito em coma ou se um sujeito acometido por um acidente vascular cerebral que lhe resultou em graves sequelas (não tem mobilidade, não fala).

No decorrer da elaboração do estudo social, o assistente social conhece singularidades da vida dos sujeitos, as quais expressam dimensões particulares e universais da vida social. Conforme Iamamoto: "O assistente social não trabalha com fragmentos da vida social, mas com indivíduos sociais que se constituem na vida em sociedade e condensam em si a vida social." (IAMAMOTO, 2004, p. 272)

E a vida social é cenário de disputas das quais é partícipe o assistente social. Portanto, é fundamental uma intervenção profissional que se edifique com base princípios do Código de Ética Profissional, construindo e alimentando estratégias que potencialize a defesa dos direitos humanos da população. Nesta perspectiva, uma análise cuidadosa e qualificada é fundamental para contribuir para que o instituto da curatela seja aplicado na medida exata de sua necessidade.

\section{Conclusão}

A Convenção sobre os Direitos da Pessoa com Deficiência ingressa em território nacional com pouco alarde. Porém, seus pressupostos são referenciados pelo Estatuto da Pessoa com Deficiência que, aprovado em 2015, firma novos paradigmas, redefine conceitos e regula a curatela a partir de um novo horizonte no qual a perspectiva do cuidado e respeito à pessoa curatelanda e curatelada se impõe. Portanto, a curatela é medida excepcional a ser aplicada na medida exata de sua necessidade.

Assim, ao juiz é imposto pela lei determinar os limites da curatela conforme as potencialidades do curatelando. Para tal, ele deve contar com avaliação técnica multidisciplinar de modo a obter pareceres profissionais que lhe ofertem subsídios para decidir sobre a pertinência de aplicar ou não a curatela.

Os pareceres técnicos precisam trazer elementos a respeito da condição de autonomia e funcionalidade dos sujeitos, o que não está necessariamente circunscrito ao terreno da medicina. Inclusive, já se superou a perspectiva de que a questão da saúde é de natureza exclusivamente médica. Contudo, considerando a hegemonia conquistada pelo saber psiquiátrico nesta temática, parece razoável vislumbrar que sua atuação será perpetuada. E quanto à outra especialidade que comporá o cenário da multidisciplinaridade? 
E se for necessário aplicar o instituto da curatela, é preciso definir quem será o curador. Esta sempre foi a demanda principal endereçada ao assistente social no contexto das ações de curatela. Mas neste novo cenário firmado pelo EPD, inúmeros desafios e possibilidades de intervenção se apresentam ao assistente social, convocando uma reconfiguração do modo de operar da categoria neste novo contexto da curatela à luz do EPD. E conforme Fávero,

O que é solicitado ao profissional assistente social não é o conhecimento jurídico, ou a interpretação da lei, mas o conhecimento específico do Serviço Social, de forma que sua apresentação, por meio do estudo social, registrado em um relatório ou laudo, contribua para a justa aplicação da lei. (FAVERO, 2014, p. 52)

Embora aprovado, a materialização do EPD não é tarefa serena e se insere no plano das disputas por diferentes projetos societários e profissionais. $\mathrm{O}$ debate sobre a avaliação multidisciplinar não está circunscrita à curatela. Atinge territórios defendidos por disciplinas, defesas de mercado de trabalho e de prerrogativas profissionais e se potencializa nesta conjuntura. Inclusive, com significativa expressão no contexto do Instituto Nacional do Seguro Social (INSS), no qual se edifica proposta de extinção do Serviço Social, o que poderia resultar na avaliação de deficiência somente pela medicina. O novo conceito de deficiência e de capacidade civil também tem inúmeras implicações, na valorização e respeito à igualdade e à autonomia dos sujeitos com deficiência, mas certamente também com repercussão, diante das atuais reformas em curso, na esfera dos benefícios previdenciários e assistenciais.

As mudanças normativas expressam disputas na sociedade. E o EPD trouxe mudanças significativas que atingem o modo de operar da sociedade brasileira, bem como do Serviço Social. Entretanto, não se trata tão somente de assegurar o espaço de atuação do assistente social na temática da curatela, mas, fundamentalmente, de alimentar as lutas por uma perspectiva de atuação coletiva, pela defesa de direitos, pelo efetivo reconhecimento de que pessoas com deficiência devem ser reconhecidas e tratadas como sujeitos de direitos, com plena capacidade e autonomia. E que a curatela precisa de fato se constituir como instrumento de cuidado e não de cerceamento de direitos. 


\section{Referências}

ABREU, C. B. Curatela \& Interdição Civil. Rio de Janeiro: Lúmen Júris, 2009.

ALVES, J. C. M. Direito Romano. 14. ed. Rio de Janeiro: Forense, 2008.

ARBEX, D. Holocausto Brasileiro. São Paulo: Geração Editorial, 2013.

BRASIL. Lei $\mathbf{n}^{\mathbf{0}} \mathbf{7 . 8 5 3}$, de 1989. Dispõe sobre o apoio às pessoas portadoras

de deficiência, sua integração social, sobre a Coordenadoria Nacional para Integração da Pessoa Portadora de Deficiência - Corde, institui a tutela jurisdicional de interesses coletivos ou difusos dessas pessoas, disciplina a atuação do Ministério Público, define crimes, e dá outras providências. Disponível em:

$<\underline{\text { http://www.planalto.gov.br/ccivil 03/leis/L7853.htm }>\text {. Acesso em: } 26 \mathrm{dez} .}$ 2019.

. Lei $\mathbf{n}^{\circ}$ 8.213, de 24 de julho de 1991. Dispõe sobre os Planos de Benefícios da Previdência Social e dá outras providências. Disponível em: $<$ http://www.planalto.gov.br/ccivil 03/leis/18213cons.htm>. Acesso em: 26 dez. 2019.

Lei $\mathbf{n}^{\mathbf{0}} \mathbf{1 0 . 2 1 6}$, de 2001. Dispõe sobre a proteção e os direitos das pessoas portadoras de transtornos mentais e redireciona o modelo assistencial em saúde mental. Disponível em: < http://www.planalto.gov.br/ccivil 03/leis/ leis 2001/110216.htm >. Acesso em: 26 dez. 2019.

Lei n⿳ 10.406, de 2002. Institui o Código Civil. Disponível em: <http://www.planalto.gov.br/ccivil 03/leis/2002/110406compilada.htm>. Acesso em: 26 dez. 2019.

. Decreto-lei no 6949, de 2009. Promulga a Convenção Internacional sobre os Direitos das Pessoas com Deficiência e seu Protocolo Facultativo. Lex: , , , 2009. Disponível em: < http://www.planalto.gov.br/ccivil 03/ _ato2007-2010/2009/decreto/d6949.htm >. Acesso em: 26 dez. 2019.

. Lei no 13.146, de 2015. Institui a Lei Brasileira de Inclusão da Pessoa com Deficiência (Estatuto da Pessoa com Deficiência). Disponível em: $<$ http://www.planalto.gov.br/ccivil 03/ ato2015-2018/2015/lei/ 113146.htm >. Acesso em: 26 dez. 2019.

DHNET. Lei das II Tábuas. DHNET. Disponível em: $<\underline{\text { http://www.dh- }}$ net.org.br/direitos/anthist/12tab.htm >Acesso em: 26.dez.2019. 
FAVERO, E. O Estudo Social: fundamentos e particularidades de sua construção na Área Judiciária. In: CFES. O Estudo Social em Perícias, Laudos e Pareceres Técnicos. São Paulo: Cortez Editora, 2014, p. 13-64.

IAMAMOTO, M. V. Questão social, família e juventude: desafios do trabalho do assistente social na área sociojurídica. In: SALES, M. A. et alli. Política social, família e juventude: Uma questão de direitos. São Paulo: Cortez Editora, 2004, p. 261-314.

SÁ, M. de F. F. de; MOUREIRA, D. L. M. A Capacidade dos Incapazes: saúde mental e uma releitura da teoria das incapacidades no direito privado. Rio de Janeiro: Lúmen Júris, 2011. 